\title{
A novel organic-inorganic hybrid monolith for trypsin immobilization
}

\author{
WU ShuaiBin ${ }^{1,2}$, MA JunFeng ${ }^{1,2}$, YANG KaiGuang ${ }^{1}$, LIU JinXiang ${ }^{1,2}$, LIANG Zhen ${ }^{1}$, \\ ZHANG LiHua $^{1 *} \&$ ZHANG YuKui ${ }^{1}$ \\ ${ }^{1}$ Key Laboratory of Separation Sciences for Analytical Chemistry, National Chromatographic R\&A Center, \\ Dalian Institute of Chemical Physics, Chinese Academy of Sciences, Dalian 116023, China; \\ ${ }^{2}$ Graduate University of Chinese Academy of Sciences, Beijing 100049, China
}

Received May 13, 2010; accepted August 17, 2010

\begin{abstract}
In proteomics, attention has focused on various immobilized enzyme reactors (IMERs) for the realization of high throughput digestion. In this report, a novel organic-inorganic hybrid monolith based IMER was prepared in a $100 \mu \mathrm{m}$ i.d. capillary with 3-glycidoxypropyltrimethoxysilane (GLYMO) as the monomer and tetraethoxysilane (TEOS) as the crosslinker. Trypsin immobilization was achieved via the reaction between vicinal diol groups, which were obtained from hydrolysis of epoxy groups, and the amino groups of trypsin. Bovine serum albumin was digested thoroughly by this IMER in $47 \mathrm{~s}$. After micro-reverse phase liquid chromatography-tandem mass spectrometry ( $\mu$ RPLC-MS/MS) analysis and database searching, beyond 35\% sequence coverage was obtained, and the result was comparable to that of $12 \mathrm{~h}$ in solution digestion. The present IMER has potential for high throughput digestion.
\end{abstract}

immobilized enzyme reactor, organic-inorganic hybrid monolith, protein identification, HPLC-MS/MS

Citation: Wu S B, Ma J F, Yang K G, et al. A novel organic-inorganic hybrid monolith for trypsin immobilization. Sci China Life Sci, 2011, 54: 54-59, doi: $10.1007 / \mathrm{s} 11427-010-4108-\mathrm{z}$

Shot gun proteomics is an important analytical approach. High efficiency enzymatic digestion is crucial for this approach. Traditionally, this digestion is performed in various buffer solutions [1,2], and effective digestion requires a long digestion time (4-24 h). Real protein mixtures are very complex compared to individual proteins, which means they required even longer digestion time and higher enzyme to substrate ratios. As proteomics develops, automatic and high throughput analysis is becoming popular. Therefore, new digestion methods are required to replace solution digestion.

Enzyme immobilization [3] is a promising strategy for high throughput digestion. It allows the digestion time to be reduced to a few minutes or even seconds. For online diges-

*Corresponding author (email: lihuazhang@dicp.ac.cn) tion systems, manual handling is minimized because of direct connection between the immobilized enzyme reactors (IMERs) and other related subassemblies. In addition, the IMERs can be reused hundreds of times. To date, many IMERs [4-12] have been designed and applied successfully. Monolith based IMERs [8-12] prepared in capillaries have been particularly popular because of the monolithic relatively high binding capacity for enzymes, low backpressure, biological inertia, and mechanical stability.

In our previous work, an organic-inorganic hybrid IMER [13] based on amino groups for enzyme immobilization was developed, and showed high digestion activity. Here, another organic-inorganic hybrid IMER with classical epoxy groups was prepared to achieve more direct trypsin immobilization. The digestion performance demonstrated that this IMER had superior digestion activity and stability to our 
previous IMER.

\section{Materials and methods}

\subsection{Materials and chemicals}

The fused-silica capillary $(100 \mu \mathrm{m}$ i.d. $\times 375 \mu \mathrm{m}$ o.d.) was purchased from Sino Sumtech (Hebei, China). Tetraethoxysilane (95\%, TEOS) and 3-glycidoxypropyltrimethoxysilane (>97\%, GLYMO) were obtained from Acros organics (Geel, Belgium). Chitosan was supplied by Potuo Biomedical Corp. Polyethylene glycol 20000 (PEG 20000) was used as the porogen. A synthetic decapeptide, C-myc (97\%, EQKLISEEDL), was ordered from Dalian Biotech Company Ltd. (Dalian, China). L-(Tosylamido-2-phenyl) ethyl chloromethyl ketone (TPCK) treated trypsin (bovine pancreas), bovine serum albumin (BSA, bovine serum), cytochrome $c$ (horse heart), apo-transferrin (bovine), sodium azide, iodoacetamide, and dithiothreitol (DTT) were purchased from Sigma-Aldrich (St. Louis, MO, USA). All organic solvents were HPLC grade. Water was purified by a Milli-Q system (Millipore, Molsheim, France).

\subsection{Instrumentation}

A precise syringe pump (Baoding Longer Pump Company, Baoding, China) was used to push samples through the IMERs, and a temperature controller (ZW-column oven, Dalian Elite Analytic Instruments Co., Ltd.) was utilized to maintain the temperature at $37^{\circ} \mathrm{C}$. All conventional chromatographic experiments were performed in a high-performance liquid chromatograph (HPLC) system equipped with a UV detector (Jasco, Tokyo, Japan). An Allegra 64R centrifuge (Beckman coulter. Inc., Miami, USA) was used for sample purification. A $\mu$ capillary reverse phase liquid chromatography-electrospray ionization-tandem mass spectrometry (RPLC-ESI-MS/MS) system was constructed by combining nanoRPLC with a Finnigan LCQ XL IT mass spectrometer (Thermo-Fisher, San Jose, CA, USA).

\subsection{IMER preparation}

TEOS $(672 \mu \mathrm{L})$ was mixed with $200 \mu \mathrm{L}$ of methanol and 10 $\mu \mathrm{L}$ of $0.5 \mathrm{~mol} \mathrm{~L}{ }^{-1} \mathrm{HCL}$ until the solution was homogeneous. The solution was placed in a water bath at $60^{\circ} \mathrm{C}$ for $15 \mathrm{~min}$. The solution was cooled to room temperature and $\mathrm{H}_{2} \mathrm{O}$ (216 $\mu \mathrm{L})$ was added. This solution reacted in a water bath at $60^{\circ} \mathrm{C}$ for $4 \mathrm{~h}$. The TEOS sol was stored in the refrigerator at $-20^{\circ} \mathrm{C}$. Chitosan solution was added to improve the monolithic hydrophilicity. To make the chitosan solution $60 \mathrm{mg}$ of chitosan was dissolved in $5940 \mu \mathrm{L}$ of doubly distilled $\mathrm{H}_{2} \mathrm{O}$ and $60 \mu \mathrm{L}$ of pure acetic acid. This solution was vortex mixed for $5 \mathrm{~min}$, and then sonicated for $10 \mathrm{~min}$. The solution was centrifuged at $4000 \mathrm{r} \mathrm{min}^{-1}$ for $30 \mathrm{~min}$, and the supernatant was collected and stored at $-80^{\circ} \mathrm{C}(5 \mathrm{~mL})$. The chitosan solution was poured into a $50 \mathrm{~mL}$ flask chilled in an ice bath to $0^{\circ} \mathrm{C}$. GLYMO $(470 \mu \mathrm{L})$ was added dropwise to the chitosan solution with slowly electromagnetic agitation. The solution was reacted at $65^{\circ} \mathrm{C}$ for $18 \mathrm{~h}$ with electromagnetic agitation. The GLYMO sol $(90 \mu \mathrm{L})$ was mixed with $8 \mathrm{mg}$ of PEG20000 and vortexed for $20 \mathrm{~s}$, and sonicated for $10 \mathrm{~min}$ to obtain a homogeneous solution. This was followed by addition of $100 \mu \mathrm{L}$ of the TEOS sol, vortex mixing for $20 \mathrm{~s}$, and sonication for $10 \mathrm{~min}$. The final solution was injected into a $100 \mu \mathrm{m}$ i.d. capillary. After both ends of the capillary were sealed by silicon rubbers, it was placed at $40^{\circ} \mathrm{C}$ for $18 \mathrm{~h}$. The capillary was subsequently rinsed with ethanol and water for $30 \mathrm{~min}$ each to elute the pore-forming solvent. Trypsin solution $\left(2 \mathrm{mg} \mathrm{mL}^{-1}\right)$ in phosphate buffered saline (PBS) (100 $\left.\mathrm{mmol} \mathrm{L}^{-1}, \mathrm{pH} 10.0\right)$ containing $0.05 \mathrm{~mol} \mathrm{~L}^{-1}$ benzamide was pumped into the capillary at $4{ }^{\circ} \mathrm{C}$ for $4 \mathrm{~h}$. The microreactor was stored at $4{ }^{\circ} \mathrm{C}$. For the IMER, the immobilized amount of trypsin was calculated by measuring the difference between the concentrations of enzyme in the supernatant before and after the immobilization by Bradford assay.

\subsection{Protein digestion}

BSA was dissolved in $50 \mathrm{mmol} \mathrm{L}^{-1} \mathrm{NH}_{4} \mathrm{Ac}(\mathrm{pH} 8.0,100 \mu \mathrm{L})$ containing $8 \mathrm{~mol} \mathrm{~L}^{-1}$ urea and then reduced in $10 \mathrm{mmol} \mathrm{L}^{-1}$ dithiothreitol for $1 \mathrm{~h}$ at $56^{\circ} \mathrm{C}$. The solution was cooled to room temperature, and the proteins' cysteines were alkylated in the dark in $20 \mathrm{mmol} \mathrm{L}^{-1}$ iodoacetic acid for $30 \mathrm{~min}$ at $37^{\circ} \mathrm{C}$. This was followed by the dilution with $50 \mathrm{mmol}$ $\mathrm{L}^{-1} \mathrm{NH}_{4} \mathrm{Ac}(\mathrm{pH} 8.0,900 \mu \mathrm{L})$ to reduce the urea concentration to $<1 \mathrm{~mol} \mathrm{~L}{ }^{-1}$. This solution was stored at $-80^{\circ} \mathrm{C}$. The in-solution digestion was performed by adding trypsin to the pretreated protein sample with a substrate-to-enzyme ratio of $50: 1(\mathrm{w} / \mathrm{w})$ at $37^{\circ} \mathrm{C}$ overnight. Because of the large number of sequence-specific cleavage sites in BSA, we prolonged the incubation time to $12 \mathrm{~h}$. Finally, $2 \mu \mathrm{L}$ of formic acid was added to the solution to terminate the reaction.

\subsection{HPLC and MS analysis}

All experiments for quantitative analysis of C-myc were performed on an HPLC system equipped with a UV detector. The HPLC column $(4.6 \mathrm{~mm}$ i.d. $\times 150 \mathrm{~mm}, 5 \mu \mathrm{m}$, pore size $80 \AA$ ) was packed with octadecyl silane ODS-2. The mobile phase was (A) water with $0.1 \%$ trifluoroacetic acid (TFA) and (B) 95\% acetonitrile (ACN) with $0.1 \%$ TFA at a flow rate of $1.0 \mathrm{~mL} \mathrm{~min}{ }^{-1}$. The mobile phase gradient from 0-30 min was $18 \%-22 \% \mathrm{~B}$. The injection volume was $5 \mu \mathrm{L}$ and the detection wavelength was $214 \mathrm{~nm}$. Each measurement was repeated twice for precision. A $\mu$ HPLC-ESIMS/MS system for protein identification was constructed. 
For standard proteins the HPLC conditions were as follows: injection volume, $2 \mu \mathrm{L}$; separation column, $300 \mu \mathrm{m}$ i.d. $\times 15$ cm, $5 \mu \mathrm{m}$, pore size $300 \AA$; column packing material, ODS; mobile phase, (i) $2 \% \mathrm{ACN}$ containing $0.1 \%$ formic acid, (ii) $98 \%$ ACN containing $0.1 \%$ formic acid; mobile phase flow rate, $5 \mu \mathrm{L} \mathrm{min}{ }^{-1}$; mobile phase gradient, 0 min $2 \% \mathrm{~B}, 10$ $\min 2 \%$ B, $15 \min 10 \%$ B, $55 \min 40 \%$ B, $65 \min 80 \%$ B, $70 \mathrm{~min} 80 \% \mathrm{~B}$. The MS conditions were as follows: voltage, $3 \mathrm{kV}$; capillary temperature, $150^{\circ} \mathrm{C}$; collision energy, $35 \%$. After the peptides eluted from the microcapillary column, they were introduced directly into the ESI-MS.

\subsection{Database searching}

Total ion chromatograms and mass spectra were recorded on a PC equipped with Xcalibur software version 1.4 for $\mathrm{LCQ}^{\mathrm{DUO}}$. Mass calibration and tuning were performed in positive ion mode. One micro scan was set for each MS and MS/MS scan. All MS and MS/MS spectra were acquired in the data dependent mode. The MS was set as one full MS scan followed by three MS/MS scans on the three most intense ions for LCQ. The dynamic exclusion function was set as follows: repeat count 2 , repeat duration $30 \mathrm{~s}$, and exclusion duration $180 \mathrm{~s}$. The tandem mass spectra analysis and protein database searching were operated with Bioworks
3.1 software for $\mathrm{LCQ}^{\mathrm{DUO}}$. Protein identification was performed using BioWorks 3.1 software for LCQ. We searched myoglobin and other standard proteins from the equine and bovine 2 databases. Cysteine residues were searched as static modification of 57.0215 Da. The peptides were filtered utilizing the standard: Xcorr was higher than 1.9 for singly charged peptides, 2.2 for doubly charged peptides, and 3.75 for triply charged peptides.

\section{Results and discussion}

\subsection{Preparation and characterization of organic-inor- ganic monolith}

Sol-gel chemistry is frequently used to prepare IMERs. In our earlier study, an organic-inorganic hybrid matrix was synthesized using TEOS and 3-aminopropyltriethoxysilane. This IMER was applied for trypsin immobilization, and was very effective at digesting proteins. In this report, we prepared an organic-inorganic hybrid IMER using TEOS and GLYMO as precursors. PEG20000 was selected as the porogen after optimization. Moreover, chitosan was added to improve the hydrophilicity. The preparation procedures are outlined in Figure 1. Because of the strong polarity of the

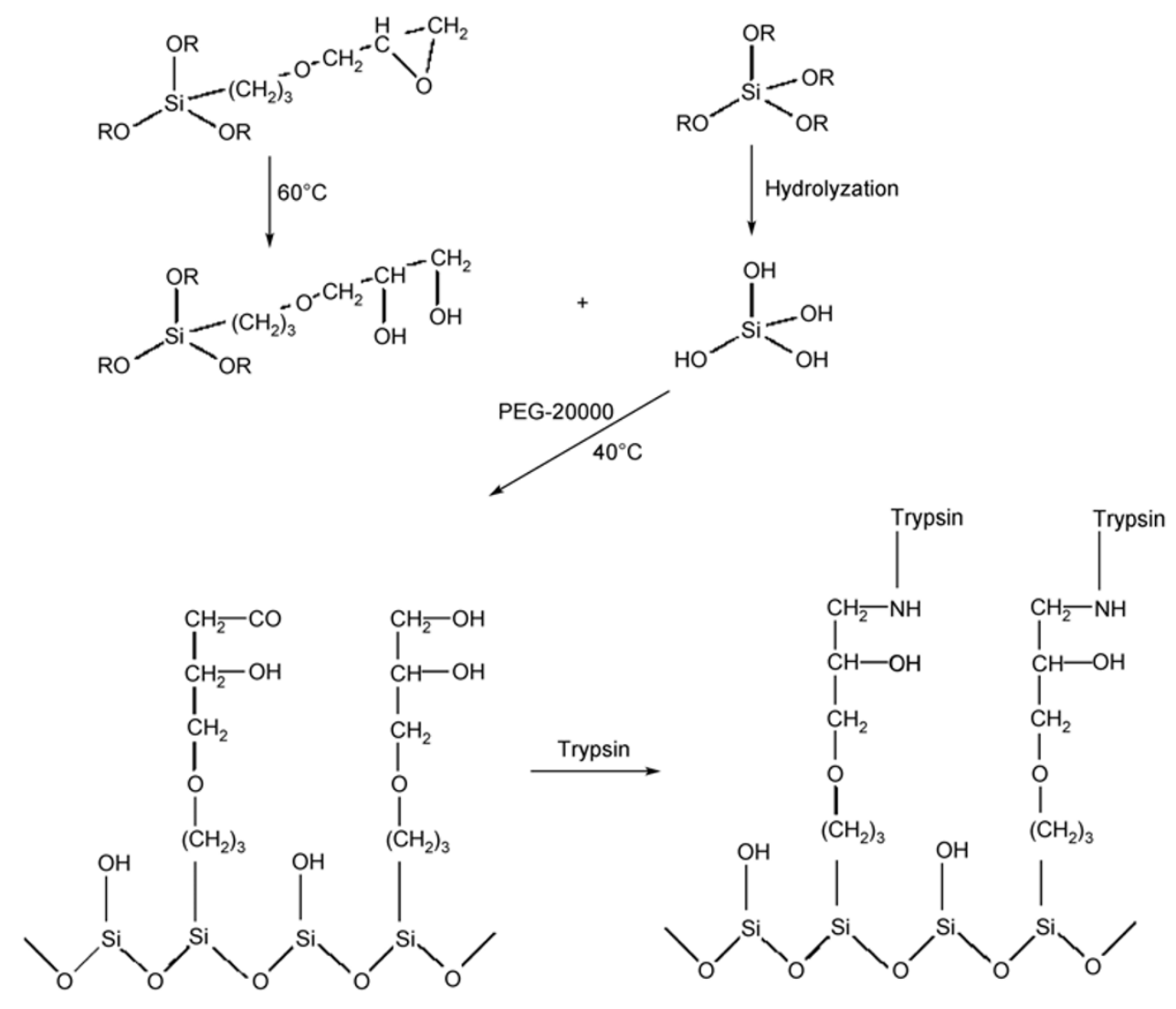

Figure 1 Schematic diagram for IMER preparation. 
GLYMO molecules, a transparent gel was formed when GLYMO and TEOS were mixed directly for the sol-gel preparation. Consequently, the prepared capillary column is not very permeable. Therefore, the GLYMO and TEOS sols were hydrolyzed first, and then mixed together in an optimized proportion. Table 1 presents the optimization process in the last preparation phase. With $120 \mu \mathrm{L}$ of GLYMO, sol phase separation did not occur, which resulted in single-phase solid gel that could not be tightly attached to the inner wall of the capillary. To address this problem, the volume of TEOS sol was increased from 90 to $110 \mu \mathrm{L}$. A satisfactory result was obtained with $100 \mu \mathrm{L}$ of TEOS, but with more or less induced poor mechanical stability (column B) or unacceptable permeability (column D). Therefore, column $\mathrm{C}$ was synthesized, followed by trypsin immobilization. For accurate calculation of the immobilized enzyme amount, four $\mathrm{C}$ columns with identical lengths were prepared, and a series of standard protein solutions $(\mathrm{pH} 8.3$ ) with different concentrations were used for calibration. The results demonstrated that on average $0.8 \mu \mathrm{g}$ of trypsin was immobilized over $1 \mathrm{~mm}^{3}$ of the sol-gel support.

Table 1 Proportion optimization for monolithic matrix preparation

\begin{tabular}{cccccc}
\hline Monolith & $\begin{array}{c}\text { GLYMO } \\
\text { gel }(\mu \mathrm{L})\end{array}$ & $\begin{array}{c}\text { TEOS gel } \\
(\mu \mathrm{L})\end{array}$ & $\begin{array}{c}\text { PEG20000 } \\
(\mathrm{mg})\end{array}$ & $\begin{array}{c}\text { Backpressure } \\
(\mathrm{MPa})\end{array}$ & $\begin{array}{c}\text { Mechanical } \\
\text { intensity }\end{array}$ \\
\hline A & 120 & 70 & 8 & $<1$ & Poor \\
B & 100 & 90 & 8 & $<1$ & Poor \\
C & 90 & 100 & 8 & $1-5$ & Proper \\
D & 80 & 110 & 8 & $>20$ & Hard \\
\hline
\end{tabular}

\subsection{Digestion activity}

The synthetic decapeptide C-myc, which can be efficiently cleaved by trypsin, was employed as the digestion substrate to test the digestion activity of the IMER. The digestion conditions included gradually increased flow rates and high concentrations of $\mathrm{ACN}$ and $\mathrm{NH}_{4} \mathrm{Ac}$. The relevant chromatograms are presented in Figure 2. Until a flow rate of 800 $\mathrm{nL} \min ^{-1}\left(1.7 \mathrm{~mm} \mathrm{~s}^{-1}\right)$, a peak for undigested C-myc appeared, which revealed digestion activity by trypsin. Afterward, 50\% ACN was added to the substrate solution, and it was digested by the same capillary IMER at $800 \mathrm{~nL} \mathrm{~min}^{-1}$. Unsurprisingly, large numbers of C-myc could not be digested in these harsh conditions. High concentrations of ACN can reduce the activity of enzymes, and even partly denature enzymes. Proteolytic digestion was then conducted in the presence of $1 \mathrm{~mol} \mathrm{~L}^{-1} \mathrm{NH}_{4} \mathrm{Ac}$ mixed with $3 \mathrm{mg} \mathrm{mL}^{-1} \mathrm{C}$-myc. The digestion result showed that the digestion activity of trypsin was recovered. The addition of $1 \mathrm{~mol} \mathrm{~L}^{-1} \mathrm{NH}_{4} \mathrm{Ac}$ did not have such serious impact on trypsin activity. Trypsin digestion still occurred in some degree in the presence of salts. Therefore, the sol-gel column is a robust matrix in terms of trypsin immobilization.

BSA (MW, $66 \mathrm{kD}$ ) was chosen as a model protein for further investigation of the digestion activity of trypsin immobilized into the organic-inorganic hybrid matrix. The flow rate through IMER or residence time of substrate to enzyme is a crucial factor that affects the digestion result. For the prepared IMER, the flow rates ranged from 100 to $500 \mathrm{~nL} \mathrm{~min}{ }^{-1}$. The corresponding residence times were from 0.8 to $3.9 \mathrm{~min}$. The effluents from the microreactor were collected and analyzed by ESI-MS/MS. Figure 3 displays the detailed identification information of BSA tryptic digests using IMER $\left(500 \mathrm{~nL} \mathrm{~min}^{-1}\right)$. As can be seen, the samples were clearly identified at flow rates from 100 to $500 \mathrm{~nL}$ $\min ^{-1}$. When the flow rate increased to $300 \mathrm{~nL} \mathrm{~min}^{-1}$ there was a transition in the relationship between the flow rate and sequence coverage or unique peptide number. The fac-

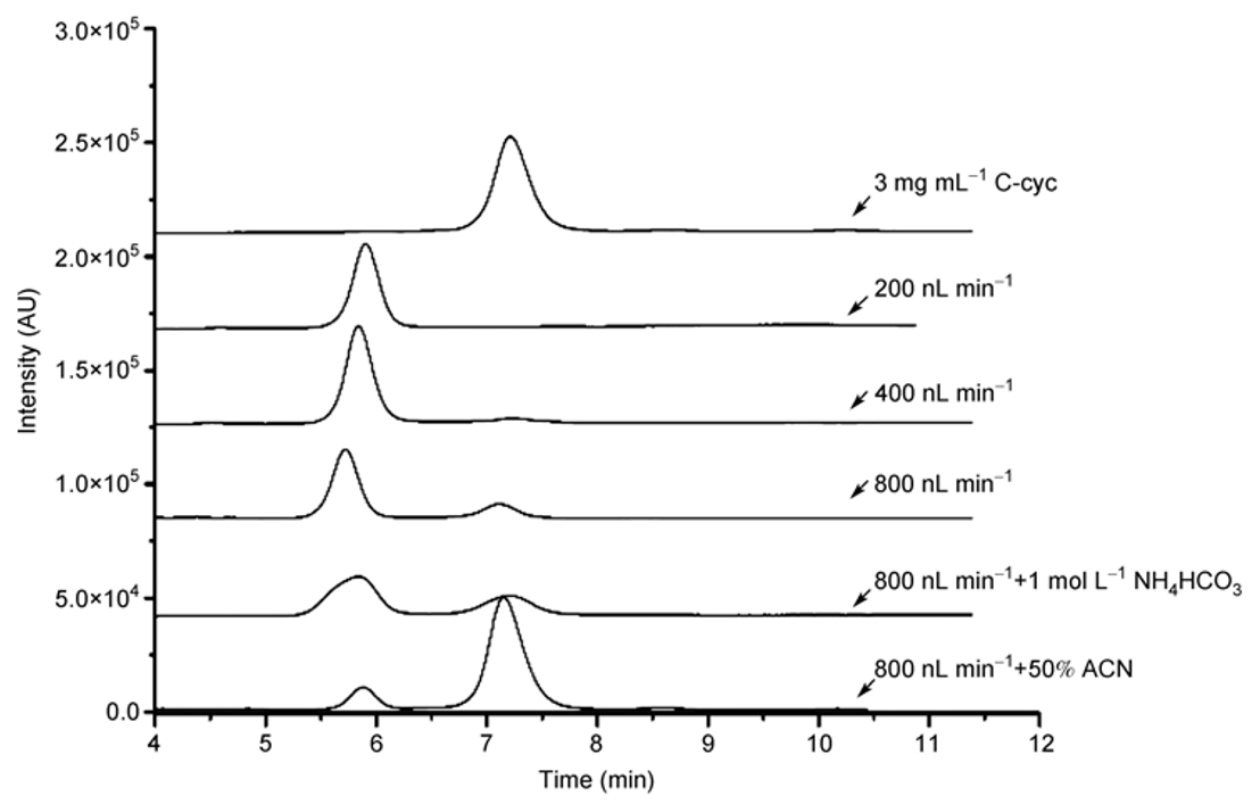

Figue 2 HPLC spectra of C-myc digestion. IMER, $5 \mathrm{~cm}, 100 \mu \mathrm{m}$ i.d. 


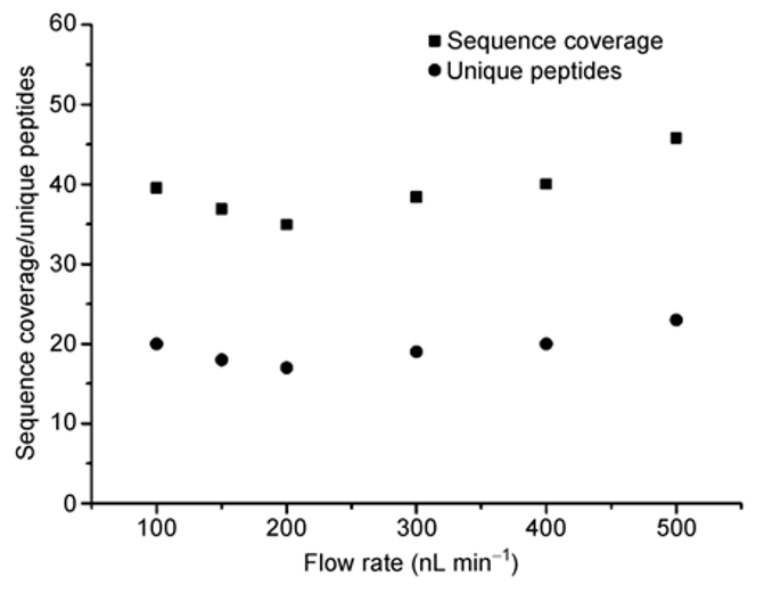

Figure 3 Influence of digestion flow rates on the digestion of BSA by IMER. Database searching was performed using bovine2.fasta. The sample injected was $2 \mu \mathrm{L}$ of $1.47 \mathrm{nmol} \mathrm{mL} \mathrm{LSA}^{-1} \mathrm{BS}$ in $50 \mathrm{mmol} \mathrm{L}^{-1} \mathrm{NH}_{4} \mathrm{Ac}-\mathrm{NH}_{4} \mathrm{OH}$ buffer ( $\mathrm{pH} 8.0$ ). The IMER was $5 \mathrm{~cm} \times 100 \mu \mathrm{m}$ i.d. The incubation time was $47 \mathrm{~s}$ in solution for $16 \mathrm{~h}$. The trypsin to protein ratio was 1:50. Separation conditions are detailed in Materials and methods section.

tors inducing this transition probably include a change in residence time and mass diffusion resistance. At low flow rates, the residence time is the most important factor affecting digestion, and at high flow rates, the mass diffusion resistance predominates.

To investigate the repeatability of digestion with the IMER, three consecutive digestions were performed with a flow rate of $300 \mathrm{~nL} \mathrm{~min}{ }^{-1}$. All digestions used the same $\mu$ RPLC-MS/MS system for separation. The relative standard deviation (RSD) of sequence coverage was calculated. The RSD was $3.9 \%$, which is satisfactory for such a big protein. This result indicated that the stability of the digestion was relatively good.

\subsection{Escherichia coli digestion}

Freshly extracted $E$. coli cells $(8 \mu \mathrm{g})$ [14] in a protein mixture were digested using the organic-inorganic hybrid IMER (10 cm length). It is well known that $E$. coli is a convincing model for investigation of IMER. The digestion products were separated and analyzed by ESI-MS/MS using strict multiple database searching thresholds. The corresponding RPLC chromatogram is presented in Figure 4. The 121 unique peptides and resultant 84 proteins were identified by database searching, with MW ranging from 4 to $180 \mathrm{kD}$ and $\mathrm{pI}$ ranging from 4.5 to 10.5 . With an increased sample injection amount, more proteins are expected to be identified. This result means that this IMER has a huge potential to achieve high throughput proteome digestion.

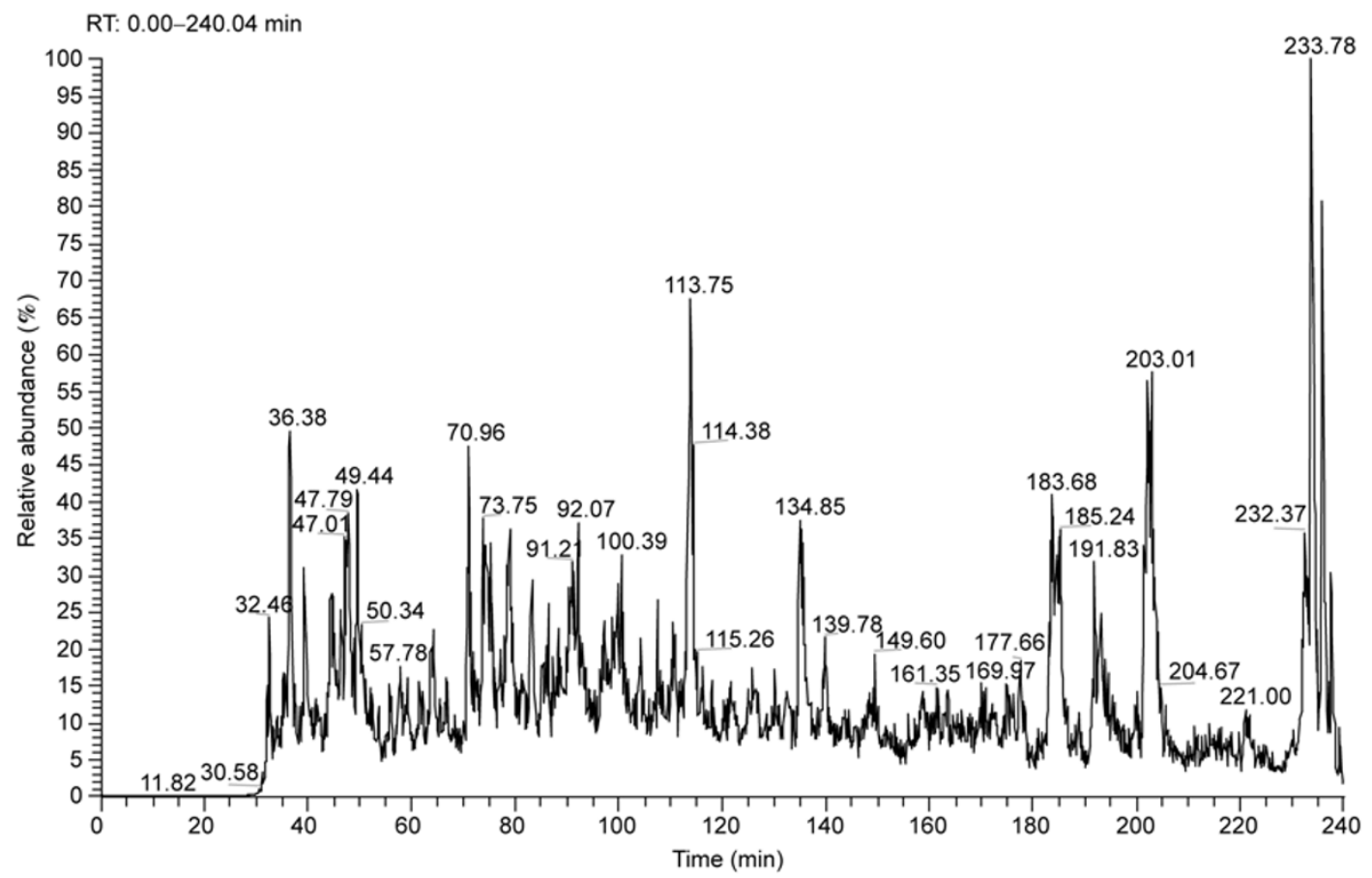

Figure 4 Base peak chromatogram of the E. coli extract. Digestion conditions: column, $10 \mathrm{~cm} \times 100 \mu \mathrm{m}$ i.d.; mobile phase flow rate, $300 \mathrm{~nL}$ min ${ }^{-1}$; temperature, $25^{\circ} \mathrm{C}$. The $E$. coli protein concentration was $0.4 \mathrm{mg} \mathrm{mL}^{-1}$, the injection volume was $20 \mu \mathrm{L}$, and the flow rate was $5 \mu \mathrm{L}$ min ${ }^{-1}$. This was followed by a 60 min elution with $0 \% \mathrm{~B}$. The separation was performed using the following gradient conditions: $0 \%-10 \% \mathrm{~B}$ in $10 \mathrm{~min}, 10 \%-40 \% \mathrm{~B}$ in $200 \mathrm{~min}$, and $40 \%-80 \%$ B in $10 \mathrm{~min}$. The final wash of the C18 column was performed with $80 \% \mathrm{~B}$ for $20 \mathrm{~min}$. The MS condition voltage was $2.0 \mathrm{kV}$. The LCQ-IT MS was operated in positive ion mode, and the capillary temperature was $150^{\circ} \mathrm{C}$. Database searching was performed using Final_e.coli.fasta. RT, retention time. 


\section{Conclusion}

An organic-inorganic hybrid monolith based IMER was prepared in capillary with a reliable mechanical stability and chromatography permeability. The trypsin activity was maintained. It digested $E$. coli proteins in $1 \mathrm{~min}$. This IMER is promising for the development of an automated online digestion device in proteomics.

This work was supported by the National Natural Science Foundation of China (Grant Nos. 20935004 and 20775080), National Basic Research Program of China (Grant No. 2007CB914100), and Knowledge Innovation Program of Chinese Academy of Sciences (Grant No. KJCX2YW.H09).

1 Aaron A K, Michael J M. Effects of modified digestion schemes on the identification of proteins from complex mixtures. J Proteome Res, 2006, 5: 695-700

2 Hervey, Strader M B, Hurst G B. Comparison of digestion protocols for microgram quantities of enriched protein samples. J Proteome Res, 2007, 6: 3054-3061

3 Byrne R E, Scanu A M. Soluble and immobilized trypsin as structural probes of human plasma high-density lipoproteins: Enzyme properties and kinetics of proteolysis. Biochemistry, 1983, 22: 2894-2903

4 Li Y, Yan B, Deng C H, et al. Efficient on-chip proteolysis system based on functionalized magnetic silica microspheres. Proteomics, 2007, 7: 2330-2339
5 Li Y, Xu X Q, Deng C H, et al. Immobilization of trypsin on superparamagnetic nanoparticles for rapid and effective proteolysis. J Proteome Res, 2007, 6: 3849-3855

$6 \mathrm{Li} \mathrm{Y}$, Yan B, Deng C H, et al. On-plate digestion of proteins using novel trypsin-immobilized magnetic nanospheres for MALDI-TOF-MS analysis. Proteomics, 2007, 7: 3661-3671

7 Cooper G W, Chen J Z, Li Y, et al. Membrane-based nanoscale proteolytic reactor enabling protein digestion, peptide separation, and protein identification using mass spectrometry. Anal Chem, 2003, 75: 1067-1074

8 Slysz G W, Lewis D F, Schriemer D C. Detection and identification of sub-nanogram levels of protein in a nanoLC-trypsin-MS system. J Proteome Res, 2006, 5: 1959-1966

9 Calleri E, Temporini C, Perani E, et al. Trypsin-based monolithic bioreactor coupled on-line with LC/MS/MS system for protein digestion and variant identification in standard solutions and serum samples. J Proteome Res, 2005, 4: 481-490

10 Sakai-Kato K, Kato M, Toyooka T. On-line trypsin-encapsulated enzyme reactor by the sol-gel method integrated into capillary electrophoresis. Anal Chem, 2002, 74: 2943-2949

11 Slysz G W, Schriemer D C. Blending protein separation and peptide analysis through real-time proteolytic digestion. Anal Chem, 2005, 77: 1572-1579

12 Duan J C, Sun L L, Liang Z, et al. Rapid protein digestion and identification using monolithic enzymatic microreactor coupled with nano-liquid chromatography-electrospray ionization mass spectrometry. J Chromatogr A, 2006, 1106: 165-174

13 Ma J F, Qiao X Q, Deng Q L, et al. Organic-inorganic hybrid silica monolith based immobilized trypsin reactor with high enzymatic activity. Anal Chem, 2008, 80: 2949-2956

14 Han M J, Lee S Y. The Escherichia coli proteome: Past, present, and future prospects. Microbiol Mol Biol R, 2006, 7: 362-439

Open Access This article is distributed under the terms of the Creative Commons Attribution License which permits any use, distribution, and reproduction in any medium, provided the original author(s) and source are credited. 